IP Periodica Polytechnica Civil Engineering

60(4), pp. 669 680 2016

DOI: $10.3311 /$ PPci.8821

Creative Commons Attribution (1)

RESEARCH ARTICLE

\section{On the Centering Eccentricity of the MOM Gi-B3 gyrotheodolite}

\author{
Gergely Szabó
}

Received 20-11-2015, revised 06-01-2016, accepted 06-01-2016

\begin{abstract}
The gyrotheodolite type MOM Gi-B3 has been examined to determine the effects of systematic and random errors due to centering and setup eccentricities. A new bifunctional centering device was manufactured for the said instrument using a centering tip to ensure centering on a pillar and a spigot to attach a reflector onto it and thus enable to determine the gyrotheodolite's position in an engineering surveying network directly. Precise horizontal angle measurements and forward intersection were used to determine eccentricities of the different centering devices used with the MOM Gi-B3 surveying instrument. In this paper I present the instrument's construction and its centering devices, geodetic fundamentals, the examinations and their results. Finally I state conclusions and form suggestions for use.
\end{abstract}

\section{Keywords}

centering eccentricity $\cdot$ centering tip $\cdot$ gyrotheodolite $\cdot$ intersection

\section{Gergely Szabó}

Department of Geodesy and Surveying,

Faculty of Civil Engineering,

Budapest University of Technology and Economics,

Múegyetem rkp. 3, H-1111 Budapest, Hungary

e-mail: gszabo@agt.bme.hu

\section{Introduction}

The gyrotheodolite type MOM Gi-B3 supplied with a mechanism to autotrack the gyro's oscillation and analogous optical readout units is the last gyrotheodolite manufactured in Magyar Optikai Múvek (Hungarian Optical Works) in quantity production. The manufacturer's specification [1] states a maximal standard deviation of $\sigma_{A}= \pm 5$ ” $\ldots \pm 8$ " for a single azimuth determination 11 and a reproducibility within 10" with the MOM GiB3. The application of the said gyrotheodolite came to the fore in the early 2000's in connection with the construction of the Budapest Metro Line 4. In this project the admissible breakthrough error was derived from $H= \pm 40 \mathrm{~mm}$ tolerance interval [2] and defined [3] as 1 sigma standard deviation in $\sigma_{b t}= \pm 13.3 \mathrm{~mm}$ [4]. In 2004 one has planned to carry out future azimuth determinations in the tunnel on short traverse legs of 70-150 m length and on breakthrough lengths of up to $1400-1900 \mathrm{~m} \mathrm{[4]}$. Under these circumstances was inevitable to clarify the effects of systematic and random errors on azimuth determination originating from centering and setup eccentricities of the MOM Gi-B3 gyrotheodolite. The results of this examinations were used in azimuth determinations in orientation transfer procedures performed with the MOM Gi-B3 gyrotheodolite in 2006 in the Gotthard Base Tunnel in Switzerland [5,6] and in 2007 in the construction of the Budapest Metro Line 4 and, have been to date not yet published.

\section{Fundamentals}

2.1 Accuracy, precision, repeatability, reproducibility and uncertainty

A clear definition and differentiation of the terms accuracy, precision, repeatability, reproducibility and uncertainty is vital for discussion. The following definitions are taken from the International vocabulary of metrology (VIM3) published by

\footnotetext{
1 Generally, for azimuth determination, one needs to know the exact value of the instrument constant $\Delta_{2}$, determined in a calibration procedure (= determination of the instrument constant $\Delta_{2}$ ) prior to the azimuth determination. Thus, the indicated $\sigma_{A}$ can be interpreted as a precision (repeatability) of the gyroscope tracked by the theodolite or as a precision of the step azimuth determination in an orientation transfer procedure.
} 


\section{JCGM [7]:}

- measurement accuracy: closeness of agreement between a measured value and a true value of a measurand

- measurement precision: closeness of agreement between indications or measured values obtained by replicate measurements on the same or similar objects under specified conditions

- repeatability: measurement precision under a set of repeatability conditions ${ }^{3}$ (of measurement)

- reproducibility: measurement precision under reproducibility conditions $4^{4}$ (of measurement)

- uncertainty of measurement: non-negative parameter characterizing the dispersion of the (quantity) values being attributed to a measurand, based on the information used.

Related definitions and terms are under [7].

\subsection{The total accuracy of direction transfer using gyro-} theodolites

The centering accuracy should be discussed with respect to the total accuracy of direction transfer using gyrotheodolites. Direction transfer is affected by various impact factors and centering is just one of these factors.

The total accuracy budget of direction transfer from a reference direction to a direction (traverse leg) in tunnel using gyrotheodolites is given by Eq. (1) [8] and Eq. (2) [9]. Both examples refer to the Gotthard Base Tunnel (GBT) in Switzerland. The traverse leg lengths in GBT are $310-450 \mathrm{~m}$ [10]. Therefore the effect of the centering eccentricity in the total accuracy budget is in GBT rather minor compared to that of the Budapest Metro Line 4. Equation (1) and Eq. (2) can be equally used for the Gyromat surveying gyroscopes of the manufacturer DMT, Germany and for the MOM Gi-B3 gyrotheodolite of the former manufacturer MOM, Hungary.

$$
\begin{aligned}
& s_{\text {total }}= \\
& \sqrt{s_{\text {net }}^{2}+s_{\text {east-west.comp }}^{2}+2 s_{\text {theodolite }}^{2}+2 s_{\text {gyro }}^{2}+s_{\text {tempfunction }}^{2}}
\end{aligned}
$$

where

\footnotetext{
2 'Measurement accuracy' is sometimes understood as closeness of agreement between measured values that are being attributed to the measurand (Source: VIM 3, Paragraph 2.13, NOTE 3 [7|)

3 repeatability condition: condition of measurement, out of a set of conditions that includes the same measurement procedure, same operators, same measuring system, same operating conditions and same location, and replicate measurements on the same or similar objects over a short period of time (Source: VIM 3, Paragraph 2.20, |7|)

${ }^{4}$ reproducibility condition: condition of measurement, out of a set of conditions that includes different locations, operators, measuring systems, and replicate measurements on the same or similar objects (Source: VIM 3, Paragraph $2.24,[7])$
}

- $s_{n e t}=$ inner accuracy of a GPS-based network direction ( $\leq 0.3$ mgon $)$;

- $s_{\text {east-westcomponent }}=$ accuracy ( $1 \sigma$ standard deviation $)$ of the deflection of the vertical derived from gravimetric measurements and extrapolations. (=0.3 mgon [11]);

- $s_{\text {theodolite }}=$ accuracy of an optical direction transfer (=0.3 mgon);

- $s_{\text {gyro }}=$ inner accuracy of a gyro (0.7 mgon);

- $s_{\text {tempfunction }}=$ standard deviation of the temperature correction function of the gyro. This is a function of the temperature difference between both direction transfer stations (= $0.5 \mathrm{mgon})$.

Equation (1) gives a theoretical accuracy of $s_{\text {total }}=1.3 \mathrm{mgon}$ for the direction transfer using gyrotheodolites. [8] The total accuracy estimate in Eq. (1) can be extended with a term $s_{e}$ originating from centering eccentricities as discussed in Paragraph 4 of this paper.

A more comprehensive and more representative total accuracy estimate is possible using the concept of measurement uncertainty. The definition of the uncertainty budget due GUM [12] enables to consider effects of random and systematic errors in values of both statistical and empirical origin. Equation (2) estimates the combined standard uncertainty $u_{c}$ for the direction $t_{\text {gyro }}$ determined in direction transfer using a gyrotheodolite in the GBT [9]:

$$
\begin{aligned}
& u_{c}\left(t_{\text {gyro }}\right)=\sqrt{u_{\bar{A}_{\text {ref }}}^{2}+u_{E_{\text {lokal }}}^{2}+u_{\text {temp.corr }}^{2}+u_{\text {defl.vertical }}^{2}+u_{e}^{2}}= \\
& =\sqrt{0.35^{2}+0.59^{2}+0.2^{2}+0.3^{2}+0.31^{2}}=0.84 \mathrm{mgon}
\end{aligned}
$$

where

$u_{\text {Aref }}$ uncertainty of forward-backward gyro azimuth observations carried out on the reference direction;

$u_{\text {E.lokal }}$ uncertainty of the gyro's lokal calibration value $E$;

$u_{\text {temp.corr }}$ uncertainty of the azimuth correction due to the temperature function of the gyro;

$u_{\text {defl.vertical }}$ uncertainty of the azimuth correction due to the variances of the deflection of the vertical;

$u_{e} \quad$ uncertainty due to the centering eccentricity (a direction measurement uncertainty originated from a linear eccentricity 5

5 The principle of the expression of the uncertainty $u_{e}$ originating from centering eccentricities of the theodolite and the target is generally the classical approach, i. e. to calculate a small angle using an assumed cross-directional centering eccentricity vector and the length of the measured direction. Nevertheless, instead of eccentricity, the centering accuracy is, using a multiplicator, transformed to uncertainty. In [9] a centering accuracy of $\mathrm{e}= \pm 0.3 \mathrm{~mm}$ (note that the gyrotheodolite is usually set on a pillar) on both ends of the reference direction (theodolite and target) with $500 \mathrm{~m}$ length and an $\mathrm{e}= \pm 2.0 \mathrm{~mm}$ in the tunnel on both ends of the measured direction with $350 \mathrm{~m}$ length are assumed. The measurement uncertainty in [9] is stated as case c of [13], thus due GUM $\mathrm{u}(\mathrm{e})=0.58 \cdot e$ which results $u_{e}=0.31 \mathrm{mgon}$ in the tunnel [9]. Analogously, the uncertainty on the reference direction is $u_{e}=0.03$ mgon [9] which is negligible. 
For practical use a tolerance interval with a confidence level of $95 \%$ can be defined with introducing the extending factor $k=2$ and using $u_{c}$ and resulting the extended measurement uncertainty $U[9]$ :

$$
U\left(t_{\text {gyro }}\right)=k \cdot u_{c}\left(t_{\text {gyro }}\right)=2 \cdot 0.84 \mathrm{mgon}= \pm 1.68 \mathrm{mgon} .
$$

\subsection{Construction of the MOM Gi-B3 gyrotheodolite and its centering devices}

The four main units of the MOM Gi-B3 gyrotheodolite equipment are the $A$ tripod or pillar adapter (with an inner hole diameter larger than the housing of the gyro unit), the $B$ gyroscope unit (north-seeking unit) and the $C$ theodolite (direction/angle measurement unit) mounted directly above $B$ and the $D$ external power supply and transformer [15]. $D$ is supplied with external $12 \mathrm{~V}$ automobile batteries. Units $B$ and $C$ are generally and during operation mechanically connected, their joint is considered as stiff. (Fig. 11 and Fig. 2)

The $E$ spacer-ring-shaped base plate of the theodolite including three leveling footscrews having studs atop is separated from the theodolite and should be placed on the top of the tripod. The upper plate of the pillar adapter is identical with $E$. By setting up the instrument the bottom of the theodolite should be placed with its three radially cut $\mathrm{v}$-shaped slots onto the three studs of E. (Fig. 1 and Fig. 2)

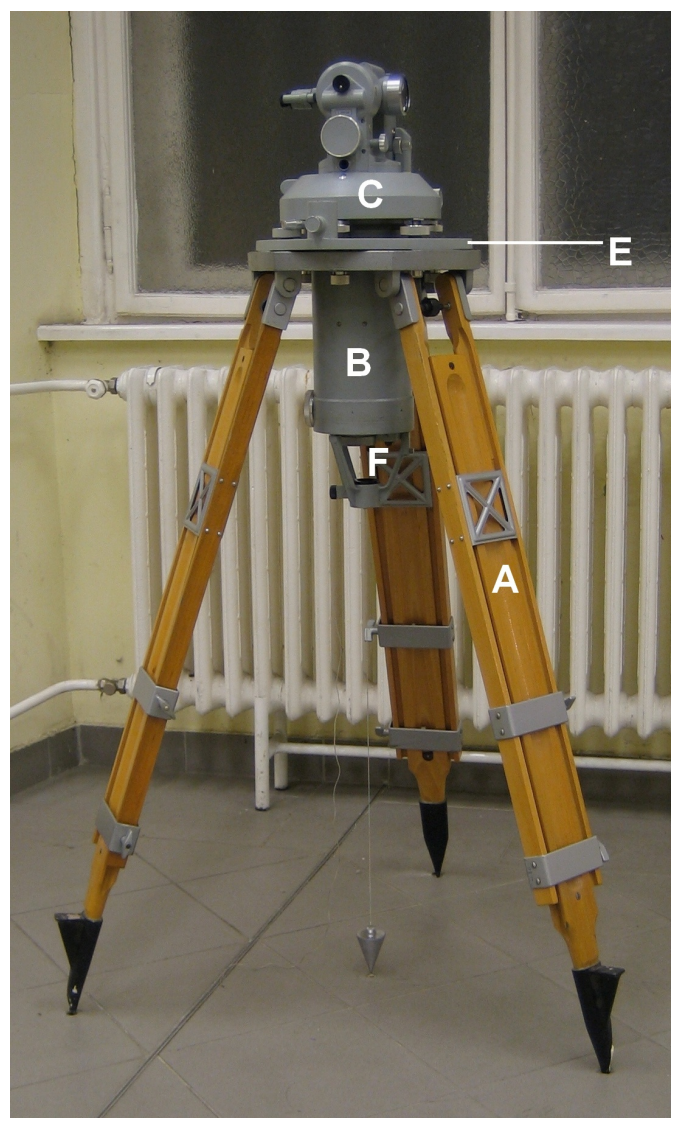

Fig. 1. MOM Gi-B3 gyrotheodolite with string plummet on its tripod

The $C$ theodolite of the MOM Gi-B3 gyrotheodolite is a converted MOM Te-B43 theodolite featuring a hollow-spindle ver-

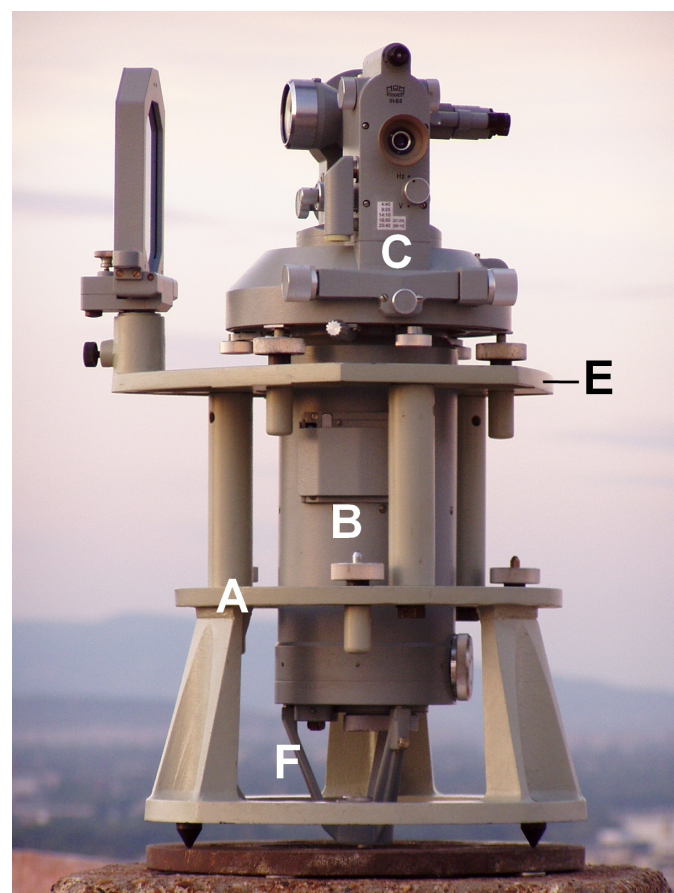

Fig. 2. MOM Gi-B3 gyrotheodolite centered on a pillar using pillar adapter

tical axle and a built-in autocollimator. The cylindrical shaped hollow space in the center of the alidade is open toward the bottom and enables to fit the top of the gyro-pendulum and its autocollimation mirror embedded in $B$ in the view field of the autocollimator. (The gyro-pendulum's oscillations are transferred from said autocollimation mirror through the autocollimator to the theodolite's horizontal circle. Thus, any eccentricity of the gyro-pendulum's vertical turning axis in respect to the vertical axis V or the centering device's axis C of the gyrotheodolite is indifferent to azimuth determination.) The rimmed-edge head ring of the gyro unit's cylindrical housing fits very precisely and coaxially into its socket shaped at the bottom of the theodolite and thus, to the vertical axis of the theodolite. The gyro unit can be rotated around the vertical axis of the theodolite manually before the fixing screws under the hold-up clamps on the bottom of the theodolite are tightened.

Neither the theodolite has a built-in optical plummet, nor the gyro unit has such. Different plummet-based centering devices are provided by the instrument's manufacturer to ensure the centering of the MOM Gi-B3 gyrotheodolite over a mark of a ground point. A string plummet can be attached at the bottom of the gyro unit with fixing the $F$ plummet-holder-tripod between them (Fig. 11 and Fig. 3). Another centering accessory provided is a plummet holder plate shaped as a three-blade-boomerang to be placed on the three footscrew-studs of $E$ prior to that the theodolite is placed there. The MOM Gi-B2 gyrotheodolite was equipped with a disc with integrated optical plummet, bussol and circular level which is interchangeable with the plummet holder plate of the MOM Gi-B3. The said lightweight plates are separated from the gyrotheodolite, thus it can only be assumed, that after centering with the string plummet the vertical axis of the gyrotheodolite weighing $16 \mathrm{kgs}$ will be set into the same 
plumb line as the string plummet was set before and crossing the mark of the station point ${ }^{6}$ (Note, that an additional precise leveling of the gyrotheodolite might be needed, and thus slightly changing the position of the gyrotheodolite's vertical axis and the position of $F$.) Using $F$ offers an assumably better coincidence of the plummet's plumb line with the gyrotheodolite's vertical axis, but every setting of the parts from the theodolite down to the cone end of the plumb bob might differ within some millimeters. Using different centering devices generates different centering eccentricities. It can be assumed, that none of the described three centering devices can ensure to center the vertical axis of the gyrotheodolite precisely over a mark, i. e. to meet the requirements of engineering surveying in the preferred submillimeter range. Note, that it is usually possible to work with an eccentric set up of the gyrotheodolite in a short distance from the main station mark, thus measuring eccentric directions and reduce the observations from the eccentric station onto the main station. This procedure fully eliminates the centering eccentricity, but needs, especially underground, considerably larger efforts in measuring.

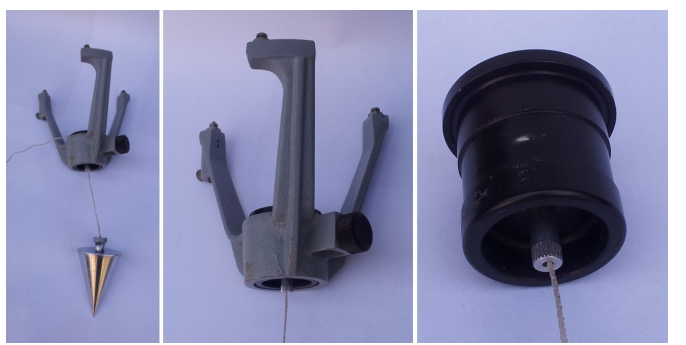

Fig. 3. The plummet holder tripod of the MOM Gi-B3 gyrotheodolite with string plummet and its details

\subsection{Centering eccentricity and its effect on azimuth deter- mination}

By definition, centering ecentricity or, in older terms, centering error is, as depicted on (Fig. 4), if the vertical axis V of the leveled theodolite does not cross the point A of the direction AP to be observed. The effect $(\delta)$ of the horizontal centering eccentricity $\delta$ is [16]:

$$
(\delta)=\arcsin \left(\frac{\delta}{d} \sin \omega\right)
$$

where $d$ is the length of the direction AP to be observed and $\omega$ is the angle of the triangle APV opposite to $d$. The change of the horizontal direction or azimuth is due to the cross-directional component of the centering eccentricity, in case of $\omega=0$ or $\omega=180^{\circ}$ the effect of the centering eccentricity $\delta>0$ is: $(\delta)=0$.

\footnotetext{
${ }^{6}$ Any device designed to be seated on the three studs of the $E$ base-plate can be seated in three different layouts. In two different layouts I have examined, the two horizontal positions of the vertical axes of the leveled MOM Gi-B3 gyrotheodolite differed by $1.7 \mathrm{~mm}$, whilst the tripod's possible instability was $<0.3 \mathrm{~mm}$. Such a difference may also occur between the vertical axis of the plumbed string plummet set by the plummet holder plate and the vertical axis of the leveled gyrotheodolite seated up after.
}

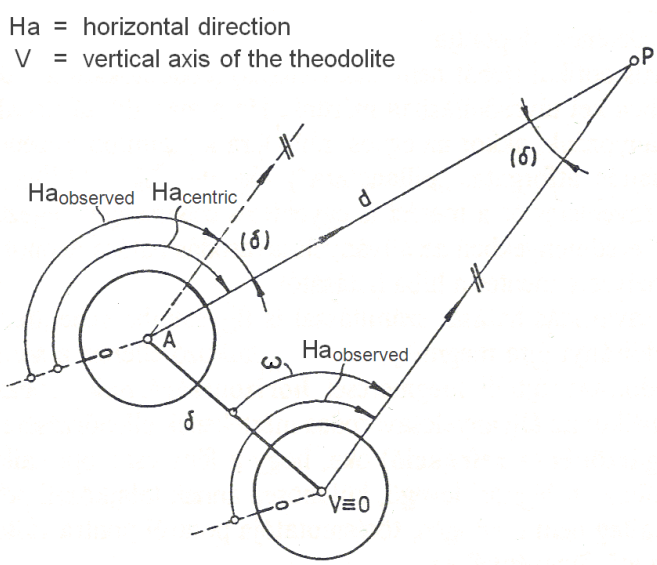

Fig. 4. Centering eccentricity $\delta$ and its effect $(\delta)$ on the observed horizontal direction [16]

Fig. 5 depicts the functional model of the MOM Gi-B3 gyrotheodolite's setting over a known point and lists the components causing centering eccentricity and causing different azimuths.

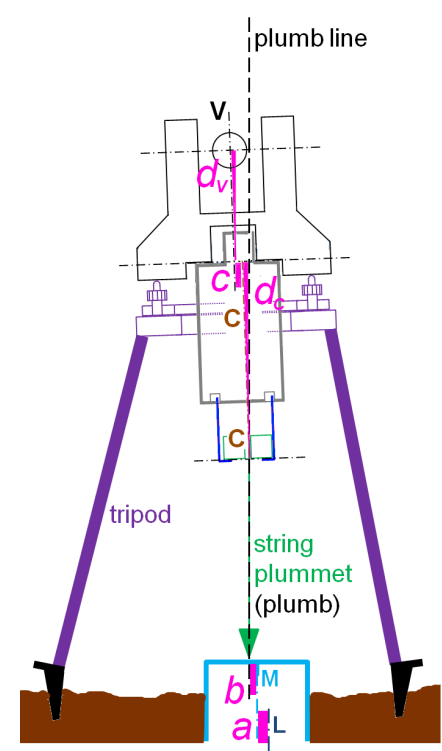

a coordinate error

b setting up eccentricity

c eccentricity of the centering device

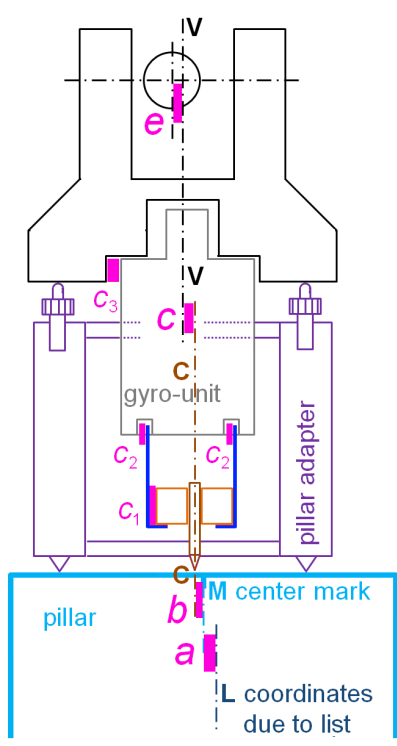

$d$ tilt of the vertical axis $V$ of the theodolite and tilt of the vertical axis $C$ of the centering device

e line of sight eccentricity

\section{The effects of the components $a b c d$ result different azimuths.}

Fig. 5. Setting of the MOM Gi-B3 gyrotheodolite over a known point. Functional model with error components, scheme.

In the following, the effect of the MOM Gi-B3 gyrotheodolite's centering eccentricity on azimuth, as a functional model is described.

In case of the MOM Gi-B3 gyrotheodolite the centering eccentricity is defined as the horizontal vector $\mathbf{e}_{M-V}$ between the plumb line crossing the mark $M$ of the station point and the vertical axis $V$ of the leveled gyrotheodolite. This vector can be divided into the residual centering eccentricity vector $\mathbf{e}_{M-C}$ and the centering device's eccentricity vector $\mathbf{e}_{C-V}$ meaning the horizontal distance between the centering device's reference point and the vertical axis $V$ of the leveled gyrotheodolite. The first 
one can be minimized by the observer with a careful centering, the size of the vector $\mathbf{e}_{C-V}$ depends on the construction, on the adjustment and on the certain setting of the centering device. (See Fig. 6)

The effect $(\delta)$ of the centering eccentricity on the azimuth determination is, as depicted on (Fig. 6), equal to the angle $\varepsilon$ of the triangle spanned by the centering eccentricity vector $\mathbf{e}_{M-V}$ and the traverse leg with its azimuth to be determined; the change of the azimuth is caused by the cross-directional centering eccentricity vector $\mathbf{e}_{c}$ derivable from the vector $\mathbf{e}_{M-V}$ and said traverse leg. In a surveying network defined by its known points coordinates the position $M$ of the station - where the centering device's $C$ axis and thus, the theodolite's vertical axis $V$ are aligned to - usually differs from the position $L$ defined in the coordinate list. (The difference is the vector $\mathbf{e}_{L-M}$.) Hence, the eccentricity effectively influencing the determination of the instrument constant $\Delta_{2}$ - the inverse task of azimuth determination by the MOM Gi-B3 gyrotheodolite, performed by measuring from a station toward a direction having a known azimuth - is equal to $\mathbf{e}_{L-V}$, thus its effect is $\varepsilon$ '. However, the vectors $\mathbf{e}_{L-M}$ and $\mathbf{e}_{L-V}$ are not known. The length of the $\mathbf{e}_{L-M}$ vector can be described by features like the standard deviations of the known point's coordinates, the standard deviations of the observed directions or by relative error parameters of the linear deviations derived from the distance and direction measurements performed in the network.

Fig. 6 depicts an assumed, possible layout of the centering and the azimuth measurement or the determination of the instrument constant $\Delta_{2}$ performed by the MOM Gi-B3 gyrotheodolite in a surveying network. A more complicated layout occurs if one considers more than one sighted points and a random oriented position of the centering eccentricity vector $\mathbf{e}_{M-V}$. The cross-directional centering eccentricity $\mathbf{e}_{c}$ is not a normally distributed variable and can not be modeled with any of the commonly known distributions. [17]

\subsection{Elimination of centering eccentricity}

The elimination of centering eccentricity is, mathematically, to find minima of the cross-directional eccentriciy vector $\mathbf{e}_{c}$. Practically, the most efficient way to eliminate centering eccentricity is, to cut out instrument parts and circumstances causing it. E. g. the use of the pillar adapter, the centering device with centering tip I have prepared (Paragraph 3.2) and the documented instrument setting (Paragraph 4.2) ensuring orientable minimal centering eccentricity vector $\mathbf{e}_{C-V}$ all support this aim. As already mentioned, a centering eccentricity vector $\mathbf{e}_{C-V}$ laying parallel to the sighted point's direction does not change the observed azimuth of the sighted point $(\varepsilon=0)$ and thus, if such setting is possible, it can be used to eliminate the change of the azimuth. Similarly, the change of the azimuth caused by centering eccentricity is neglectably small under the often occuring practical conditions, where the sighted traverse leg is long enough (see Fig. 7). In cases of having short traverse legs the previously noted eccentric set up and calculation procedure can also be used to eliminate the effect of centering eccentricity.

By extending and examining the centering devices of the MOM Gi-B3 gyrotheodolite, my aims were, to reduce the extent of the centering eccentricity vector $\mathbf{e}_{M-V}$ and its maximum into the submillimeter range and, further, to determine the extent and the orientation of the centering device's eccentricity vector $\mathbf{e}_{C-V}$ and its effect on azimuth determination.

\section{Preliminaries}

3.1 Centering with the MOM Gi-B3 gyrotheodolite, initial situation

Using a tripod or the pillar adapter and the original centering devices described in Paragraph 2.3 the centering of the MOM Gi-B3 gyrotheodolite takes place by moving the tripod, leveling with the footscrews and shifting the base plate. On a pillar usually there is no space under the gyro unit to use $F$ and a string plummet for centering (Fig.2 and Fig.9) therefore an alternative centering solution was needed. No accuracy, precision or maximal eccentricity parameters on the centering eccentricity of the original centering devices was found in the literature or in the manufacturer's brochures. I estimated the precision of the reference point positions of this devices set in replicate settings in $1 \mathrm{~mm}$ standard deviation and the maximal centering eccentricity in 2 to $3 \mathrm{~mm}$. As a comparison [18] states an accuracy of $\pm 3 \ldots \pm 5 \mathrm{~mm}$ for string plummet and $\pm 0,5 \mathrm{~mm}$ centering error for the optical plummet; [19] characterizes the laser plummet of the Leica TPS1200+ Total Stations with a centering accuracy of $1.5 \mathrm{~mm}$ at $1.5 \mathrm{~m}$ with a laser dot diameter of $2.5 \mathrm{~mm}$ at $1.5 \mathrm{~m}$. The maximal possible effect on the observed horizontal direction of an assumed centering eccentricity $\mathbf{e}_{M-V}=\mathbf{e}_{c}=2 \mathrm{~mm}$ will be less than the effect of the MOM Gi-B3 theodolite's horizontal direction measurement accuracy $7^{7}$ of \pm 1.5 " (standard deviation) [1] if measuring a traverse leg longer than $275 \mathrm{~m}$ (Fig. 6 and Fig.77.

\subsection{Constructional extensions of the centering device}

By replacing the string guiding spindle of the plummet holder tripod of the MOM Gi-B3 gyrotheodolite with a guiding spindle to hold a centering tip and a Wild-spigot I have constructed a bifunctional device (Fig. 8) for centering the gyrotheodolite on a pillar (Fig. 9) and to attach a reflector to the gyrotheodolite. The centering tips with different lengths can be slipped vertically and coaxially inside the hollow guiding spindle and clamped by a screw in the favoured position. One end of the tip is conically pointed, the other end is identically designed to a Wild-spigot (Fig. 8). The latter enables the centric attachment of a reflector with Wild-system sleeve and lock and, therefore the direct positioning of the gyrotheodolite by total stations. The parts are manufactured to a precision of $1 / 100 \mathrm{~mm}$. The guiding spindle

${ }^{7}$ horizontal direction measurement accuracy = angle measurement accuracy; e.g. [19] 


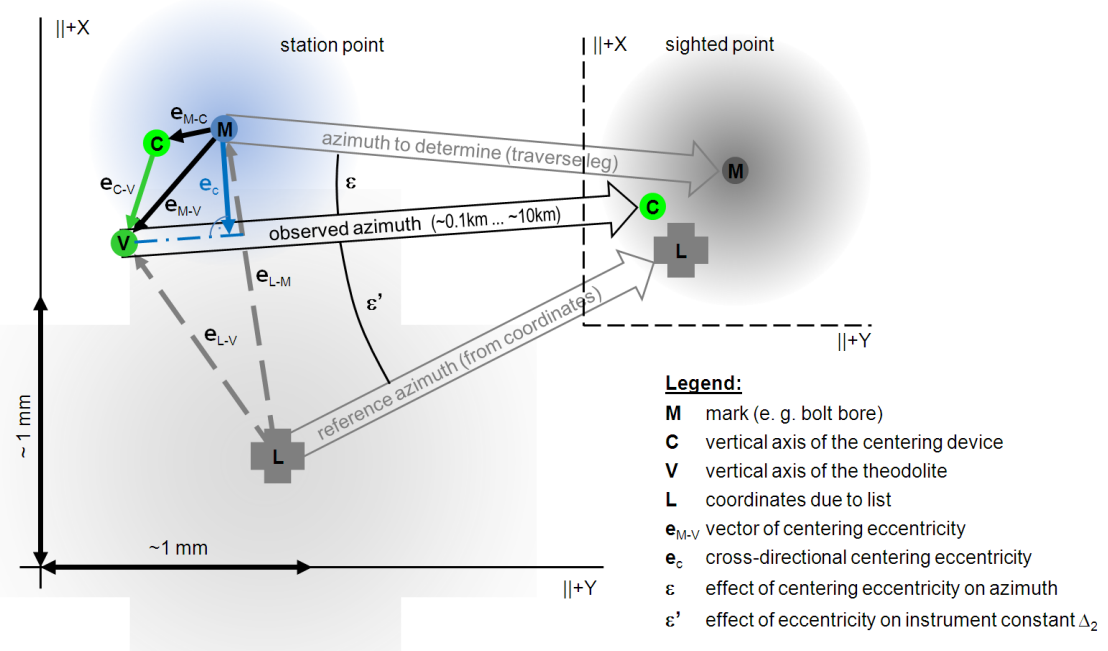

Fig. 6. Interrelationship between centering of the MOM Gi-B3 gyrotheodolite over a known point, the different azimuth definitions and their effects;

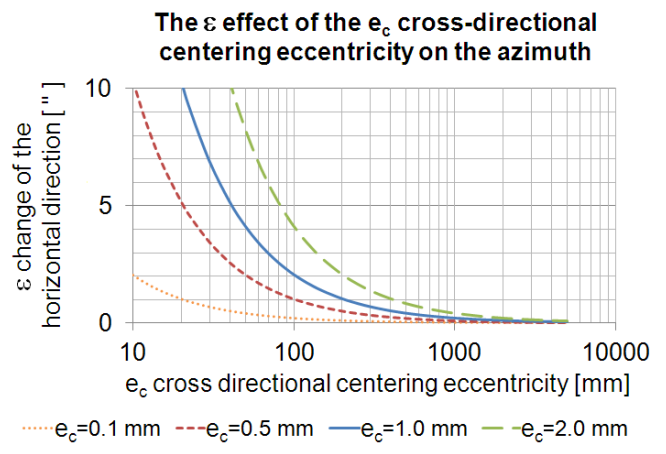

Fig. 7. The effect of the cross-directional centering eccentricity on the azimuth

also enables the attachment of a Wild-spigot-topped carrier with optical plummet ${ }^{8}$

\subsection{Preliminary knowledge on the centering devices}

The centering device as a whole, i. e. from the pointed tip of the centering device until the theodolite consists of the separate structural units theodolite, gyro unit and centering unit. (A stable tripod or pillar adapter is assumed here.) The structural elements of the string plummet as a centering unit also include the guiding spindle and the plummet holder tripod as seen on (Fig. 3). The structure of the centering device described in Paragraph 3.2 includes the centering tip, its guiding spindle and the holder tripod as depicted on (Fig. 8). Basically, the listed connecting units and parts are considered as coaxial joints. Each two connecting parts have a certain joint gap and each part has a horizontal eccentricity, thus the outcome of the centering device's eccentricity vector $\mathbf{e}_{C-V}$ depends on the sum of this horizontal eccentricities summed from the pointed tip of the centering device until the leveled theodolite's vertical axis. The vector $\mathbf{e}_{C-V}$ should not be considered as a random variable, since its outcome is significantly influenced by the operator - who joins the parts with nonrandom gaps together - and by the systematic horizontal eccentricities of the parts. To ensure the identical set-

\footnotetext{
${ }^{8}$ This was a preliminary examinated configuration, see Table 1
}

functional model (scheme, not to scale)

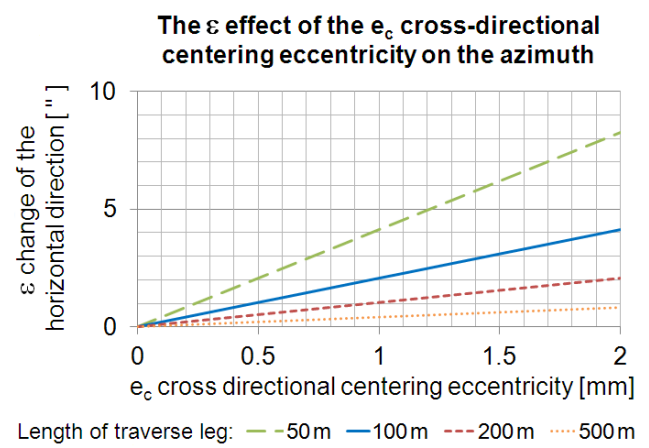

tings of the parts of a centering device as a whole in independent centering procedures, I marked the parts upon which any setting can be recorded and repeated or reproduced.

In its original spindle, the string guiding bore has a diameter of $2.3 \mathrm{~mm}$ whilst the loaded string has only a diameter of $0.8 \mathrm{~mm}$ and thus, the string plummet does not hang centric. (Fig. 3 )

\subsection{Preliminary examination of the centering devices}

The original centering devices of the MOM Gi-B3 gyrotheodolite were preliminary examined in different configurations in a simple way, as the tip positions and the center mark's projected positions of the centering devices were marked on a sheet of paper fixed on the floor or pillar below them. During this experiments the tripod, the pillar adapter, the gyrotheodolite was in standstill position relatively to the sheet of paper. One of the digitalized sheets is depicted on (Fig. 10). Opposite positions of the optical plummet and string plummet were willfully set and thus, are following a nearly regular ring pattern. Note the eccentricity of the string as mentioned at the end of Paragraph 3.3. Similarly, a systematic deviation by a non adjusted rectangular line of sight of the optical plummet or a wobbling of the line of sight of the optical plummet is assumed. The spot diameter enclosing the tip positions is connected to the precision of a device in repeated set ups (Table 11). Since this pro- 


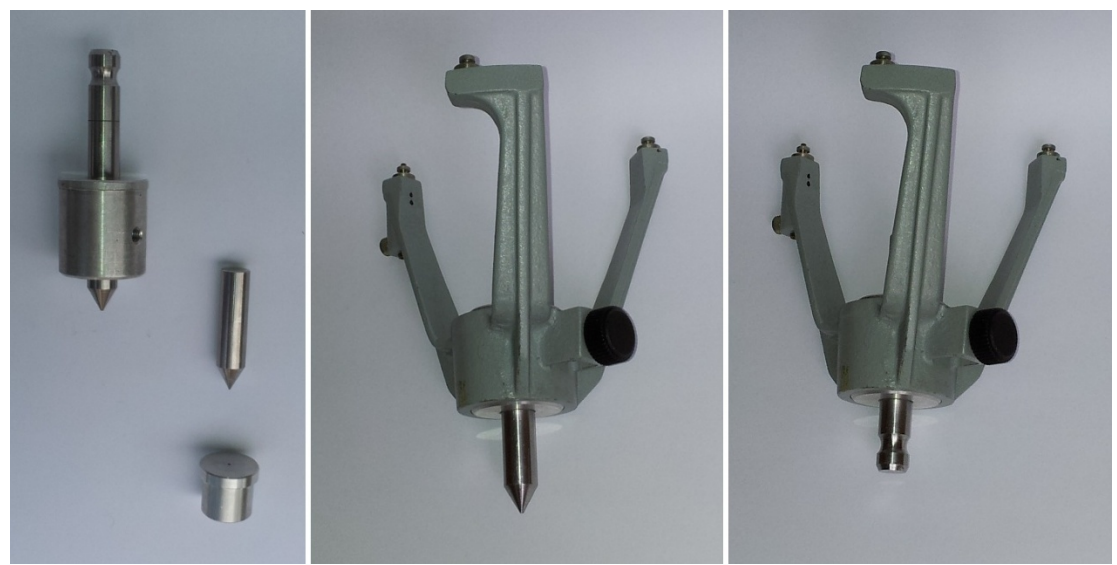

Fig. 8. Bifunctional centering tip and Wild-spigot in its guiding spindle, ing device with centering tip (middle), Reflector adapter with Wild-spigot (right) short centering tip and intermediate centering plug for $5 / 8$ " sleeve (left), Center-

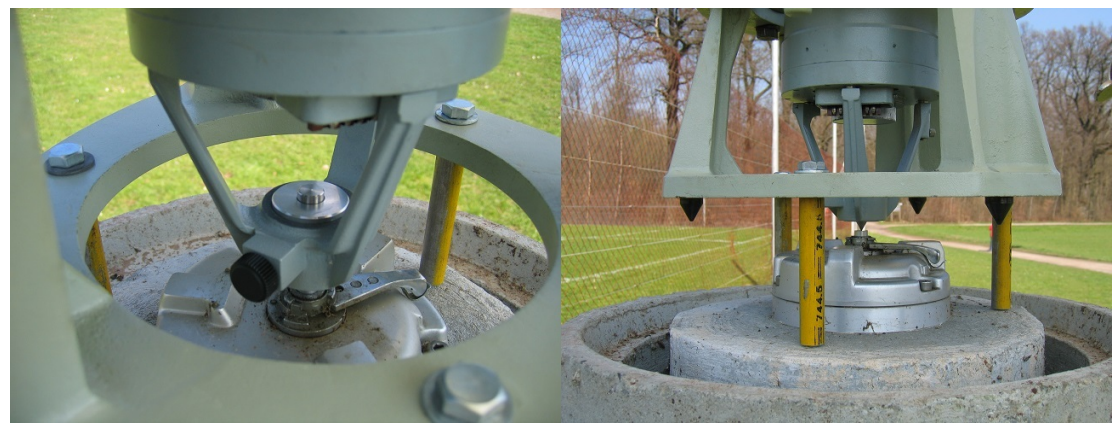

Fig. 9. Centering with the MOM Gi-B3 gyrotheodolite using the centering tip on a pillar equipped with Kern-head

cedure does not locate the position of the theodolite's vertical axis, the centering eccentricity vectors $\mathbf{e}_{C-V}$ can not be determined. Nevertheless, based on this examinations one can state, that the centering devices are eccentric and dependent on the device's setting.
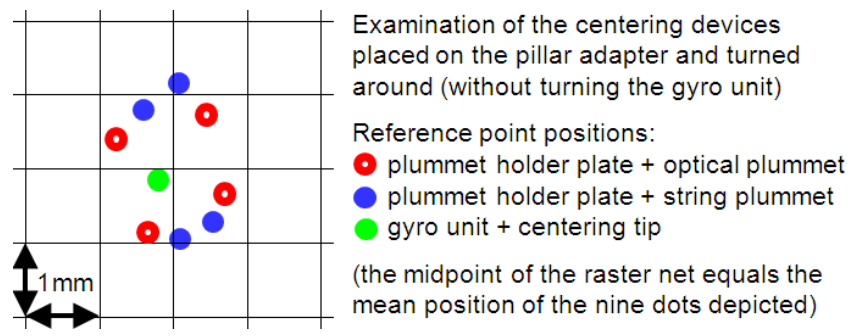

Examination of the centering devices placed on the pillar adapter and turned around (without turning the gyro unit)

Reference point positions:

- plummet holder plate + optical plummet

- plummet holder plate + string plummet gyro unit + centering tip

(the midpoint of the raster net equals the mean position of the nine dots depicted)

Fig. 10. Preliminary examination results of the centering devices placed on the pillar adapter (top view)

Based on the values of the Table 1 I estimated the extent of the centering device's eccentricity vector $\mathbf{e}_{C-V}$ being 0.3 to $2.5 \mathrm{~mm}$. This vector stands at an angle of $0^{\circ}$ to $360^{\circ}$ to the sighted point's direction. Generating $n=2000$ random pair of values in the said two intervals, I simulated the value of the cross-directional centering eccentricity $\mathbf{e}_{c}$. In this simulation the values of $\mathbf{e}_{C-V}$ can be only the 23 discrete values of the set $[0.3 ; 0.4 ; 0.5 ; \ldots ; 2.4 ; 2.5]$ in $[\mathrm{mm}]$ and the angle values of the set $[0,1 ; 2 ; \ldots ; 358 ; 359]$ in $\left[{ }^{\circ}\right]$. The simulated average value of $\mathbf{e}_{c}$ is $0.9 \mathrm{~mm}$, the simulated median of $\mathbf{e}_{c}$ is $0.8 \mathrm{~mm}$. Based on the estimated maximum value of the vector $\mathbf{e}_{C-V}=2.5 \mathrm{~mm}$, the simulated average value of $\mathbf{e}_{c}$ results $1.6 \mathrm{~mm}$, the simulated median of $\mathbf{e}_{c}$ results $1.8 \mathrm{~mm}$. The effect of $\mathbf{e}_{c}$ on the azimuth determination can be estimated from (Fig. 7).

Based on the estimated maximum value of the vector $\mathbf{e}_{C-V}=2.5 \mathrm{~mm}$, and due to GUM as published in [13] one can express the measurement uncertainty $u\left(e^{\prime}\right)$ originating from centering eccentricity. Assuming $\mathbf{e}_{c}$ as an assymetric parameter with assymetric borders $0<\mathbf{e}_{c}<2.5 \mathrm{~mm}$, one gets using the equations (6) and (11) - (14) of [13]:

$$
u\left(e^{\prime}\right)=\sqrt{u(e)^{2}+\Delta^{2}}=\sqrt{\frac{1}{3} a^{2}+\Delta^{2}}=1.4 \mathrm{~mm},
$$

where $a=1.25 \mathrm{~mm}$ and $\Delta=1.25 \mathrm{~mm}$. (For $a$ and $\Delta$ see [13].) The measurement uncertainty $u_{e}$ of the direction measurement can be calculated if the length $L$ of the measured direction is known, e. g. u(e') $=1.4 \mathrm{~mm}$ and $L=100 \mathrm{~m}$ results $u_{e}=3.0$ " (target eccentricity is not considered). Footnote 5 gives two more examples on $u_{e}$.

Assuming $\mathbf{e}_{c}$ as a symetric parameter with symetric borders $-2.5 \mathrm{~mm}<\mathbf{e}_{c}<2.5 \mathrm{~mm}$, equation (9) of [13] results the same measurement uncertainty u(e') as the value in Eq. [5] above.

The accuracy term $s_{e}$ to extend Eq. (1) can be derived analogously to $u_{e}$. Using $\mathbf{e}_{c}=0.9 \mathrm{~mm}$ and $L=100 \mathrm{~m}$ results $s_{e}=1.9$ " and $\mathbf{e}_{c}=1.6 \mathrm{~mm}$ and $L=100 \mathrm{~m}$ results $s_{e}=3.3$ ".

The change of the azimuth originating from a crossdirectional eccentricity $\mathbf{e}_{c}=0.8 \ldots 1.8 \mathrm{~mm}$ on short traverse legs like 70-150 m length is 1 " to 5 " (on $150 \mathrm{~m}$ length $\mathbf{e}_{c}=0.8 \mathrm{~mm}$ causes 1.1 " and on $70 \mathrm{~m}$ length $\mathbf{e}_{c}=1.8 \mathrm{~mm}$ causes 5.3 "), which comes additionally to the azimuth determination accuracy of \pm 5 " to \pm 8 " [1] of the MOM Gi-B3. This is not satisfactory 
Tab. 1. Configurations and results of the preliminary examinations of the centering devices

\begin{tabular}{c|c|c}
\hline & \multicolumn{2}{|c}{ Spot diameter enclosing the observed tip positions } \\
\hline Configuration & pillar adapter & tripod \\
\hline $\begin{array}{c}\text { plummet holder plate + string plummet } \\
\text { plummet }\end{array}$ & $\mathrm{D}=2.2 \mathrm{~mm}$ & not examined \\
\hline plummet holder plate + optical & $\mathrm{D}=2.0 \mathrm{~mm}$ & $\mathrm{D}=1.8 \mathrm{~mm}$ \\
\hline theodolite + gyro unit + string plummet & & $\mathrm{D}=2.7 \mathrm{~mm}$ \\
\hline theodolite + gyro unit + optical plummet & & $\mathrm{D}<1 \mathrm{~mm}$ \\
\hline theodolite + gyro unit + centering tip & & \\
\hline
\end{tabular}

when performing precise azimuth determinations and orientation transfers. An azimuth determination accuracy of 8" to 10", as a 1 sigma standard deviation is, in an engineering surveying environment, not competitive.

In order to find the optimum between the strict breakthrough requirements of the ongoing Budapest Metro Line 4 project and the field-time- and cost-intensive gyrotheodolite measurements it was a vital step to reduce the maximal centering eccentricity of the MOM Gi-B3 gyrotheodolite.

In a further simple examination, the gyrotheodolite's telescope was pointed toward the crosshair of a theodolite. Then, the conic centering mark on the top of the gyrotheodolite was sighted with the theodolite's vertical crosshair. (It was determinated later, that this mark has approximately 0.04 to $0.05 \mathrm{~mm}$ cross-directional eccentricity with respect to the line of sight of the gyrotheodolite.) Thereafter the previously introduced centering tip mounted under the theodolite and its gyro unit was rotated around by turning the gyro unit each time 90 degrees, whilst it was sighted with the theodolite's vertical crosshair. On this way, a diameter of the centering tip's trace of $0.6 \mathrm{~mm}$ was determined which layed tangential to the gyrotheodolite's line of sight. Based on this, an eccentricity vector $\mathbf{e}_{T-V}$ of the centering tip of $0.3 \mathrm{~mm}$ was estimated.

\section{Examinations}

The goals of the examinations were the following:

- The determination of the centering eccentricity of the MOM Gi-B3 gyrotheodolite using the centering tip and centric string plummet;

- The determination of the centering tip's eccentricity vector $\mathbf{e}_{T-V}$

- The determination of the centric string plummet's eccentricity vector $\mathbf{e}_{P-V}$;

- To make suggestions on the centering by means of the MOM Gi-B3 gyrotheodolite to ensure minimal centering eccentricity;

- To increase the centering accuracy respectively to decrease centering uncertainty of the MOM Gi-B3 gyrotheodolite.

\subsection{Examination by intersection}

The layout of the examinations of the centering devices of the MOM Gi-B3 gyrotheodolite is on the (Fig. 11) depicted. Two Wild T2 theodolites were used to sight toward the gyrotheodolite's crosshair and its centering devices' pointed tips. Preliminary to this sightings, the horizontal directions of the gyrotheodolite's sightings toward the vertical axes of the Wild theodolites set up on point 203 and 309 were determined and set with the slow-motion drives 9 This enabled the intersection of the gyrotheodolite's vertical axis through sightings onto the crosshair of the gyrotheodolite. The same procedure was used to sight the directions 203-309 and 309-203. The crosshairs of the Wild theodolites were lit by a torch, the MOM Gi-B3 is equipped with an autocollimation eyepiece. Both theodolites and the gyrotheodolite were carefully leveled using the plate levels. The stability of $<0.1 \mathrm{~mm}$ of the tripods and theodolites during the examinations can be assumed and is proven by the results, which reflect the circular row of positions of the examination settings.

For the intersection examinations the MOM Gi-B3 gyrotheodolite and its centering devices were installed on a tripod in a laboratory environment. The two T2s were installed on the pillar point 203 and on a tripod above the ground point 309 . During this examinations a centric guiding of the string of the string plummet was used. In the first round the initial examination position - position 1 - of the centering tip was set using the documented instrumet setting (see Paragraph 4.2). After the tip was intersected, three more positions were set by turning the gyro unit each time with 90-degrees with attached centering tip beneath. Each tip position was intersected. Hereafter, one more 90-degree turn of the gyro unit and the attachement and intersection of the reflector in position $1-i$. e. in documented instrument setting - of the centering adapter followed (Fig. 12). (During intersection measurements the reflector was carefully directed toward the theodolites.) Analogously, in a second round, positions 1 to 4 of the string plummet were set and the tip's positions intersected. Intersection sightings and observations of the horizontal direction were performed with the

\footnotetext{
9 To obtain this, the conic centering mark on the top of the Wild theodolite (e. g. 203) was sighted and its horizontal direction observed with the gyrotheodolite, then the Wild theodolite turned with 180 degrees and the mark sighted again with the gyrotheodolite. The mean of the observed two horizontal directions of e.g. Hagro-203 results the desired direction.
} 
$\mathrm{T} 2 \mathrm{~s}$ in both faces, and thus, the line of sight error and the line of sight horizontal eccentricity were compensated. The sum of the observed angles $\alpha+\beta+\gamma$ from crosshair-sightings resulted in the first examination round $179^{\circ} 59^{\prime}$ '52'.

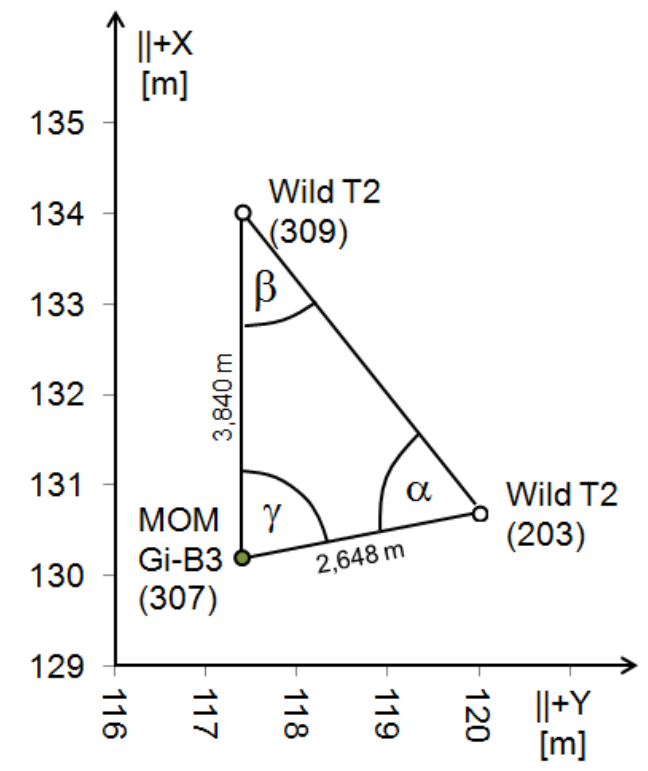

Fig. 11. Scheme of the forward intersection of the MOM Gi-B3 gyrotheodolite's vertical axis and its centering devices

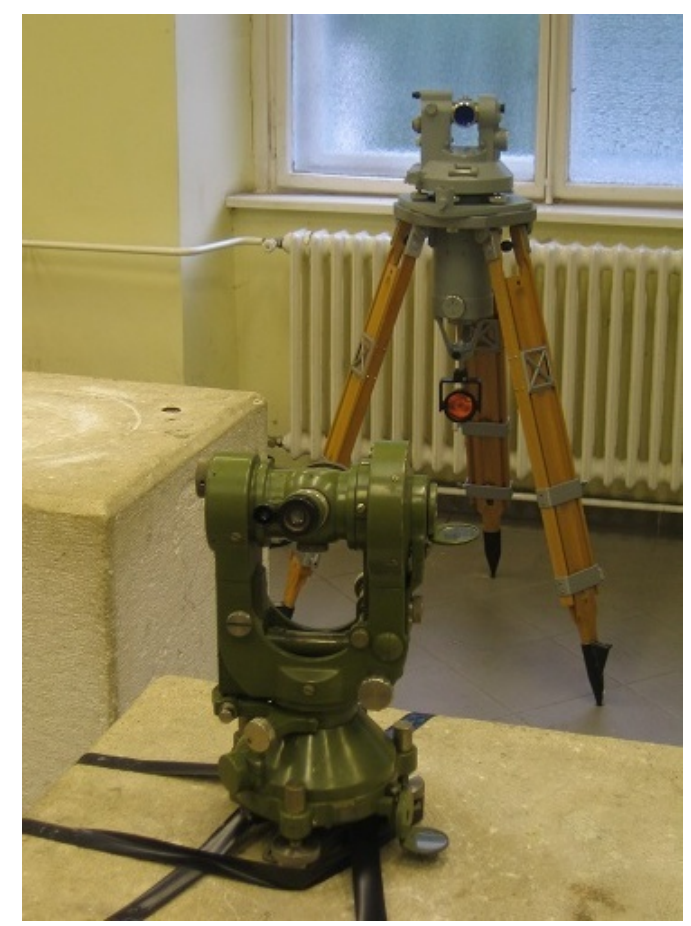

Fig. 12. Photo of the forward intersection of the MOM Gi-B3 gyrotheodolite's reflector adapter eccentricity examination (direction 203-307)

\subsection{Examination results}

In the following, statements on the MOM Gi-B3 gyrotheodolite's centering devices are formulated. The results of the examinations are the intersected point positions of the gyrotheodolite's vertical axis, of the string plummet's pointed tip and of the centering tip, laying on the horizontal plane. The results

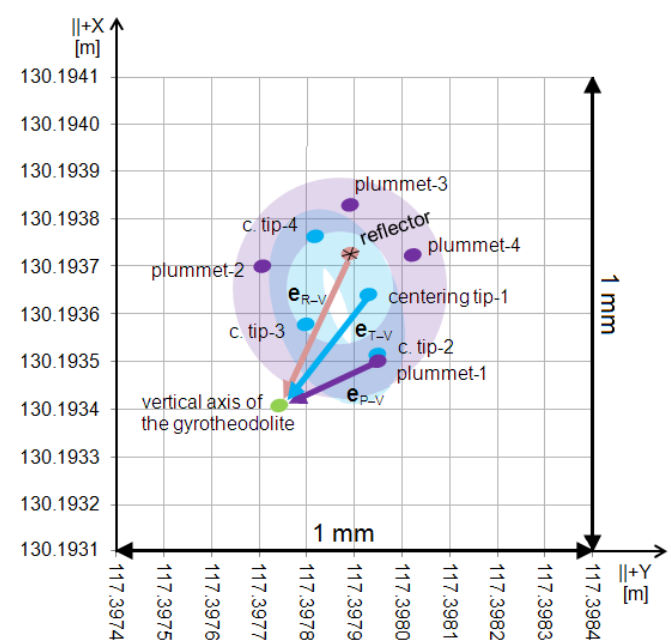

Fig. 13. Centering eccentricity examination results. Points and rings: the vertical axis of the gyrotheodolite and the different positions $1-4$ of the centering tip and the plummet's cone end determinated after three 90-degree rotations of the gyro unit. Vectors: the centering eccentricity vectors $\mathbf{e}_{C-V}$ of the centering devices belonging to the documented instrument setting.

are on (Fig. 13 depicted. The point positions are drawn with error ellipses, sized with semi-major axes $a=0,02 \mathrm{~mm}$ and semiminor axes $b=0,015 \mathrm{~mm}$; both corresponding to $1 \sigma$ standard deviations calculated (rounded estimate) due to the law of error propagation using the horizontal direction measurement accuracy of 1" of the Wild T2 theodolites and the intersection distances. The oval rings stand for the sets of the probable point positions of the string plummet's pointed tip (outer "circular" ring) and of the centering tip (inner elliptic ring). They are derived from the traces of the devices' tips rotated with the gyrounit and drawn with a "linewidth" of an error ellipse sized as $3 a$ and $3 b$, both corresponding to $3 \sigma$.

Position 1, since having minima of the centering devices' eccentricity vectors $\mathbf{e}_{T-V}$ and $\mathbf{e}_{P-V}$ was defined as the "documented instrument setting", and as such, it records the layouts of each two neighbouring parts of the centering device.

The results on the centering devices' eccentricity vectors $\mathbf{e}_{C-V}$ using the documented instrument setting (see the vectors $\mathbf{e}_{i}$ on (Fig. 13):

- If viewed from the centering device's point $C$, the vertical axis $V$ of the gyrotheodolite lays toward the horizontal-circle setting screw of the gyrotheodolite.

- The eccentricity between the centering tip and the gyrotheodolite's vertical axis is $\mathbf{e}_{T-V}=0.3 \mathrm{~mm}$.

- The eccentricity between the centric string plummet and the gyrotheodolite's vertical axis is $\mathbf{e}_{P-V}=0.3 \mathrm{~mm}$.

- The repeatability of the documented instrument setting (standard deviation) is $\sigma=0.15 \mathrm{~mm}$.

- The eccentricity of the rotation axis of the gyro unit with respect to the gyrotheodolite's vertical axis is $0.4 \mathrm{~mm}$, the diameter of the traces of the centering devices' tips rotated with 
the gyro-unit (centering tip and centric string plummet) is ca. $0.3 \mathrm{~mm}$.

- If viewed from the vertical axis $V$ of the gyrotheodolite, the reference point of the reflector attached to the centering tip's Wild-spigot lays toward the v-shaped slot No. 3 on the bottom of the theodolite.

- The eccentricity of the reference point of the reflector with respect to the gyrotheodolite's vertical axis is $\mathbf{e}_{R-V}=0.4 \mathrm{~mm}$.

The results on the centering devices' eccentricity vectors $\mathbf{e}_{C-V}$ in a random setting of the centering devices (i. e. not using the documented instrument setting):

- If viewed from the centering device's point $C$, the vertical axis $V$ of the gyrotheodolite lays roughly toward the horizontalcircle setting screw of the gyrotheodolite.

- Using the centering tip or the centric string plummet the centering devices' eccentricity vectors $\mathbf{e}_{C-V}$ with respect to the gyrotheodolite's vertical axis are minimum $\mathbf{e}_{C-V}=0.2 \mathrm{~mm}$, in average $\mathbf{e}_{C-V}=0.5 \mathrm{~mm}$ and maximum $\mathbf{e}_{C-V}=1.0 \mathrm{~mm}$.

Using a string plummet the extent of the residual centering eccentricity vector is estimated in $\mathbf{e}_{M-C}=0.5 \ldots 1.0 \mathrm{~mm}$. Thus, the estimated maximum value of the centering eccentricity of the centric string plummet in a random setting used with the MOM Gi-B3 gyrotheodolite set up on a tripod is $\mathbf{e}_{M-V}=\mathbf{e}_{M-C}+\mathbf{e}_{C-V}=2.0 \mathrm{~mm}$ and, thereby proving the initial centering eccentricity estimate of the non-centric string plummet given in Paragraph 3.1.

To generate centering eccentricity values for further use, the categories precise measurements and normal measurements were defined. The extent of the residual centering eccentricity vector is estimated in $\mathbf{e}_{M-C}=0.3 \mathrm{~mm}$ for precise measurements and $\mathbf{e}_{M-C}=1.0 \mathrm{~mm}$ for normal measurements. The centering devices' centering eccentricities were determined as $\mathbf{e}_{C-V}=0.3 \mathrm{~mm}$ in the documented instrument setting and $\mathbf{e}_{C-V}=1.0 \mathrm{~mm}$ in the random setting. Hereafter, the centering eccentricities of the centering tip and of the centric string plummet in use with the MOM Gi-B3 gyrotheodolite set up on a pillar adapter or on its tripod were calculated by simulations on the same way as described in Paragraph 3.4. (For each value of the table $n=2000$ input pairs of values were used.) See Table 2 . The calculated values embody the effect of a tilted vertical axis of the gyrotheodolite.

Since the cross-directional centering eccentricitiy $\mathbf{e}_{c}$ is not a normally distributed variable, the triple of the value corresponding to $p=68 \%$ probability covers approximately $4 / 3$ of the maximal centering eccentricity. The triple (i.e. the $p=99.7 \%$ statistical probability) of the standard deviation of the simulated $\mathbf{e}_{c}$ values covers only approximately $4 / 5$ of the maximal centering eccentricity. In fact the triple of the average crossdirectional centering eccentricity $=\mathbf{e}_{c}-$ corresponding to ca. $\mathrm{p}=58 \%$ probability - covers the maximal centering eccentricity within a few per cent. Therefore $=\mathbf{e}_{c}$ is a profound quantity to be the estimate of the accuracy term $s_{e}$ meaning the standard deviation of the direction measurement originating from centering eccentricity. Since all the three described quantities lay in a close submillimeter range and since the proportion of the centering eccentricity in direction transfers using gyrotheodolites is rather minimal there is no great practical importance which of these quantities is used as the estimate of $s_{e}$.

Using Eq. (5) and the maximal centering eccentricities in Table 2 the measurement uncertainty $u\left(e^{\prime}\right)$ originating from centering eccentricities $0.0 \mathrm{~mm} \leq \mathrm{e} \leq 0.6 \mathrm{~mm}$ results $0.35 \mathrm{~mm}$ for precise measurements and from centering eccentricities $0.0 \mathrm{~mm} \leq \mathrm{e} \leq 2.0 \mathrm{~mm}$ results $1.15 \mathrm{~mm}$ for normal measurements.

Centering eccentricities observed in a non-laboratory environment with changing temperatures might be different from the presented values determined in a constant-temperature $\left(21^{\circ} \mathrm{C}\right)$ laboratory environment. However, it is assumed that, the use of the documented instrument setting ensures centering eccentricity vectors in strongly different temperatures not differing more than the triple extent of the vectors presented in this paragraph.

\section{Conclusions}

By high-precision angular measurement the different centering devices of the MOM Gi-B3 gyrotheodolite were examined and we detected the effect of their systematic error on azimuth determination.

By converting the plummet holder of the MOM Gi-B3 gyrotheodolite into a centering device with a centering tip, a centering device was prepared and applied for centering on a pillar. The centering eccentricity of this device is characterized with an average cross-directional centering eccentricity $\overline{\mathbf{e}}_{\mathbf{c}}$ of $0.2 \mathrm{~mm}$ to $0.7 \mathrm{~mm}$ which can be used instead of the standard deviation of the centering. Using $\overline{\mathbf{e}}_{\mathbf{c}}$ and a known length $L$ of the direction to be observed one can calculate the accuracy term $s_{e}$ (standard deviation) or the uncertainty term $u_{e}$ to be used in total accuracy estimates in direction transfer using the MOM Gi-B3 gyrotheodolite.

An adapter was designed establishing centric mechanical connection between the gyrotheodolite and a reflector used for direction and distance measurement. Using the adapter and a reflector enables the determination of the position of the MOM Gi-B3 gyrotheodolite taken in an engineering surveying network by direct measurement of direction and distance. By this we have eliminated the centering and setup eccentricities, i.e. the significant sources of errors of geodetic network measurements based on gyrotheodolite measurements and direction and distance measurements.

By reducing the extent of the centering eccentricity we have improved the accuracy of centering respectively reduced the uncertainty of centering performed by the MOM Gi-B3 gyrotheodolite with one order of magnitude. By minimising the effect of the examined centering eccentricity respectively by elim- 
Tab. 2. Centering eccentricities of the MOM Gi-B3 gyrotheodolites using centering tip or centric string plummet

\begin{tabular}{ccc}
\hline \multicolumn{2}{c}{ Centering eccentricities $(\mathrm{e})$ of the MOM Gi-B3 gyrotheodolite using centering tip or centric string plummet } \\
\cline { 2 - 3 } eccentricity definition & precise measurements & normal measurements \\
\cline { 2 - 3 } & $\begin{array}{c}\text { using documented instrument setting } \\
0.0 \mathrm{~mm} \leq \mathrm{e} \leq 0.6 \mathrm{~mm}\end{array}$ & $\begin{array}{c}\text { using random instrument setting } \\
0.0 \mathrm{~mm} \leq \mathrm{e} \leq 2.0 \mathrm{~mm}\end{array}$ \\
\hline Maximal centering eccentricity & $0.6 \mathrm{~mm}$ & $2.0 \mathrm{~mm}$ \\
\hline Average cross-directional centering eccentricity & $0.19 \mathrm{~mm}$ & $0.65 \mathrm{~mm}$ \\
\hline Median $(\mathrm{p}=0.50)$ cross-directional centering \\
eccentricity
\end{tabular}

inating centering eccentricity we have increased the accuracy of the orientation transfer respectively reduced the uncertainty of the orientation transfer by means of the MOM Gi-B3 gyrotheodolite.

Suggestions on reducing the centering eccentricity performed with MOM Gi-B3 gyrotheodolites:

- The careful use of an adjusted plate level is suggested.

- The parts of the centering devices should be set as defined in the documented instrument setting. It is suggested to use a centric string plummet or the centering tip and to turn the centering device's eccentricity vector pointing toward the horizontal-circle setting screw of the gyrotheodolite as much as possible parallel to the sighting direction or traverse leg.

- It is suggested to determine the station coordinates of the gyrotheodolite by means of total station measurements performed directly on the reflector attached on the centering tip's Wild-spigot of the gyrotheodolite.

- The use of the original plummet holder plate for centering is not suggested.

\section{References}

1 Halmos F; Marczell M (ed.), MOM Gi-B3 automatikus követésú pörgettyüs teodolit, Használati és szabályozási utasítás (MOM Gi-B3 autotracking gyrotheodolite, Instructions manual), Molnár K, Magyar Optikai Múvek; Budapest, 1990.

2 Metró Tervezési Irányelvek (Metropolitan underground railway planning directive), Közlekedési Dokumentációs Vállalat (Közdok), Budapest, KPM - Közlekedés- és Postaügyi Minisztérium, Tanácsi Közlekedési Főosztály, 1979.

3 M.1. Mérnökgeodéziai szabályzat (M.1. Regulation on engineering geodesy works), MÉM Országos Földügyi és Térképészeti Hivatal, Földmérési Intézet; Budapest, 1975.

4 Szabó G, Giroteodolitok gyakorlati alkalmazásának lehetôségei a budapesti 4-es metró építésekor (Potential applications of gyrotheodolites on the construction of the Budapest Metro Line 4), In: Barna Zs, Józsa Zs (eds.), Doktori Kutatások a BME Építőmérnöki Karán, Múegyetemi Kiadó; Budapest, 2005, pp. 7-15.

5 Szabó G, Égető Cs, Kreiselmessungen mit dem MOM Gi-B3 im Gotthard-Basistunnel (gyrotheodolite measurements with the MOM Gi-B3 in the Gotthard Base Tunnel), In: Brunner F $\mathbf{K}$ (ed.), Beiträge zum 15. Internationalen Ingenieurvermessungskurs Graz, 2007, Herbert Wichmann Verlag; Heidelberg, 2007, pp. 207-212, http://www.geod.bme.hu/ ecsaba/pub/Kreiselmessungen_mit_ dem_MOMGiB3_im_Gotthard_Basistunnel.pdf

6 Szabó G, Égető Cs, Irányátvitel MOM Gi-B3 giroteodolittal a svájci Gotthárd-bázisalagút építésén (Application of MOM Gi-B3 gyrotheodolite for orientation transfer to the Gotthard Base Tunnel), In: Závoti J, Bányai L, Papp G (eds.), Geomatikai Közlemények X., MTA GGKI; Sopron, 2007, pp. 273-280, http://www.geod.bme.hu/ ecsaba/pub/Iranyatvitel_ MOMGiB3_giroteodolittal.pdf

7 International vocabulary of metrology - Basic and general concepts and associated terms (VIM) (Official name: JCGM 200:2012 or ISO/IEC Guide 99:2007), 3rd edition of the 2008 version, Joint Committee for Guides in Metrology (JCGM); 2012, pp. 16-34, http://www.iso.org/sites/ JCGM/VIM/JCGM_200e.html

8 Ingensand $\mathbf{H}$, Ryf A, Stengele R, The Gotthard Base Tunnel - a challenge for geodesy and geotechnics, IAG Symposium on Geodesy for Geotechnical and Structural Engineering, In: Kahmen H, Brückl E, Wunderlich T (eds.), Proceedings of the IAG SC4 Symposium on Geodesy for Geotechnical and Structural Engineering; Eisenstadt, Austria, 1998, http://www. geometh-data.ethz.ch/downloads/eisenstadt98.pdf

9 Heister H, Liebl W, Zur Messunsicherheit von Kreiselmessungen im Gotthard-Basistunnel, Geomatik Schweiz, 108(12), (2010), 586-593, http://www.geomatik.ch/fileadmin/redaktion/download/2010/ Fach/FA_12_2010_11.pdf

10 Stengele R, Erster Hauptdurchschlag im Gotthard-Basistunnel-Tunnelvermessung in Theorie und Praxis (First main breakthrough in the Gotthard Base Tunnel - Tunnel surveying in theory and practice), In: Brunner $\mathbf{F}$ K (ed.), Beiträge zum 15. Internationalen Ingenieurvermessungskurs Graz, 2007, Herbert Wichmann Verlag; Heidelberg, 2007, pp. 3-16, http://wWw . gruenenfelder.ch/user_websites/bsf/files/347/2007-04_IV_ 2007_Tunnelvermessung_in_Theorie_und_Praxis.pdf

11 Marti U, Schlatter A, Schätti I, Lokale Schwerefeldstudien am AlpTransit Gotthard-Basistunnel (Local gravity field studies on the AlpTransit Gotthard Base Tunnel), In: Ingensand H (ed.), Ingenieurvermessung 2004, 14th International Course on Engineering Surveying, ETH Zürich, Beiträge / Contributions, ETH Zürich; Zürich, 2004, pp. 283-288, http://www . iv2004. ethz.ch/programm/Poster/P_03_IV2004.pdf

12 Evaluation of measurement data - Guide to the Expression of Uncertainty in Measurement (GUM) (Official name: JCGM 100:2008 or ISO/IEC Guide 98-3:2008), GUM 1995 with minor corrections, Joint Committee for Guides in Metrology (JCGM), 1995, http://www.iso.org/sites/JCGM/GUM/ JCGM100/CQ45315e-html/CQ45315e.html?csnumber=50461

13 Heister H, Zur Messunsicherheit im Vermessungswesen I. und II, Geomatik Schweiz, 103(11), (2005), 604-607, http://wWw.geomatik.ch/ fileadmin/redaktion/download/2005/Fach/FA_11_2005_1.pdf

14 Heister H, Zur Messunsicherheit im Vermessungswesen I. und II, Geomatik Schweiz, 103(12), (2005), 670-673, http://www.geomatik.ch/ fileadmin/redaktion/download/2005/Fach/FA_12_2005_5.pdf 
15 Halmos F, Giroteodolitok (Gyrotheodolites), In: Fialovszky L (ed.), Geodéziai múszerek, Múszaki Könyvkiadó; Budapest, 1979, pp. 186-215.

16 Krauter A, Geodézia, 1st edition, Múegyetemi Kiadó; Budapest, 1995.

17 Hennes M, Messunsicherheiten richtig quantifizieren (GUM) (Proper quantification of uncertainties in measurements (GUM)). Tutoriumsunterlage (Tutorial, Manual), Ingenieurvermessung 14 - 17. Internationaler Ingenieurvermessungskurs, Zürich. 2014.

18 Fialovszky L, Szögmérố müszerek (Instruments of angle measurement), In: Fialovszky L (ed.), Geodéziai múszerek, Múszaki Könyvkiadó; Budapest, 1979, pp. 140-142.

19 Leica TPS1200+ Series High performance Total Station, Product brochure 738582en - V.09 - RDV, Leica Geosystems AG, Heerbrugg, Switzerland, 2009, http://www.leica-geosystems.com/downloads123/zz/ tps/tps1200/brochures/Leica_TPS1200+_brochure_en.pdf 